\title{
Thermodynamics Influence on Behavioural Pattern of Selected Medicinal Leaves
}

\author{
${ }^{* 1}$ AKPOJARO, J; ${ }^{2}$ OYEYEMI, M; ${ }^{1}$ OMOGBHEMHE, MI \\ ${ }^{I}$ Department of Mathematical and Physical Sciences, College of Basic and Applied Sciences \\ Samuel Adegboyega University, Ogwa, Edo State, Nigeria*Corresponding author: Jackson Akpojaro, jakpojaro@yahoo.com \\ ${ }^{2}$ Department of Physics, College of Natural and Applied Sciences, Benson Idahoan University, Benin City, Edo State, Nigeria
}

\begin{abstract}
Selected tropical plants leaves such as Colocasia Esculenta, Carica Papaya, Tridax, Bambusa, etc. were experimentally investigated. The plants leaves were subjected to different degrees of temperatures. We observed that some of the plants can survive in an environment with rising temperature while some cannot survive when the temperature is fast increasing. We found that Colocasia Esculenta has the highest resistance mean compared to the other tropical leaves. This is followed by Carica papaya, while Tridax Procumbens and Bambusa Vulgaris are the least in mean with 0.231 and 0.241 respectively; they show lack of moisture and lack of adequate $\mathrm{H}_{2} \mathrm{O}$. It was concluded that the effect of thermodynamics is severe in some plants like Tridax Pprocumbens. The 25\% percentile change in masses shows that at the same temperature, Manihot Esculenta and Tridax Procumbens were affected negatively.
\end{abstract}

DOI: https://dx.doi.org/10.4314/jasem.v22i2.4

Copyright: Copyright (C) 2018 Akpojaro et al. This is an open access article distributed under the Creative Commons Attribution License (CCL), which permits unrestricted use, distribution, and reproduction in any medium, provided the original work is properly cited

Dates: First received 02 August 2017; Received in revised form 23 January 2018; Accepted 04 February 2018

Keywords: Temperature, Thermodynamics, Energy transfer, Colocasia Esculenta, Carica papaya

It is widely held that in the physical sciences the laws of thermodynamics had a unifying effect similar to that of the theory of evolution in the biological sciences (Bettini, 2017). What is intriguing is that the prediction of one seems to contradict the predictions of others. Thermodynamics is built on the study of energy transfers that can be strictly resolved into two distinct components, heat and work, specified by macroscopic variables (Reif, 1965). Though thermodynamics originated in the study of cyclic non-equilibrium processes such as the working of heat engines ( $\mathrm{Wu}, 1969$ : Lucas, 2015a), study of the subject gradually revealed that the notion of heat is inextricably tied to the notion of thermodynamic equilibrium (Smith, Van Ness, and Abbott, 2005). Thermodynamics is well understood and validated for systems in thermodynamic equilibrium, but as the systems of interest become further and further from thermodynamic equilibrium, their thermodynamical study becomes more and more difficult. Systems in thermodynamic equilibrium have very well experimentally reproducible behaviour, and as interest moves further towards non-equilibrium systems, experimental reproducibility becomes more difficult. The second law of thermodynamics suggests a progression from order to disorder, from complexity to simplicity, in the physical universe (Haase, 1969; Hoch, 2011). Yet biological evolution involves a hierarchical progression to increasingly complex form of living systems, seemingly in contradiction to the second law of thermodynamics. Whether this discrepancy between the two theories is only apparent or real is the question to be considered.

Plants are living organisms that host numerous micro-organisms which are economically viable and destructive (Al-Shemmeri, 2010; Singal and Singal, 2009). It becomes paramount to investigate their strength and viability when subjected to heat under intense thermal effect. Thermodynamics is the science which deals with energy. The world today expresses transformation of matter and energy. Be this medical or chemical (Clark, 2004), the first law of thermodynamic - the principle of the conservation of energy - tells us that the total energy of universe or any isolated part of it will be the same after any such transformation as it was before (Lucas, 2015b; Bettini, 2016 ). From the first law of thermodynamics, the change in the energy of the system is equal to the work done on or by the system and the heat flow into (or out) the system mechanical work and energy are interchangeable, this implies that the energy may be converted into mechanical work as in a steam engine, or mechanical work can be converted into energy as in the heating of a canon which occurs as its barrel is bored (Purcell, 1977). 
The second law (Gyftopoulos and Beretta, 2005) of the thermodynamics describes the flow of in processes which are irreversible. The physical significance of the second law is that the energy flow in such processes is always toward a more uniform distribution of the energy of the universe. The burning of gasoline, converting energy "rich" compounds (hydrocarbons) into energy "lean" compounds carbon dioxide $\left(\mathrm{CO}_{2}\right)$ and water $\left(\mathrm{H}_{2} \mathrm{O}\right)$ is a second illustration of this principle (Arovas, 2013).

Plants' leaves have played significant roles in tradomedicine, some at low temperature while some at high temperature. Carica Papaya leaves have been discovered to act as a strong herbal medicine for the cure of Ulcer (Ahmad, Fazal, Ayaz et al., 2011). Different plants' leaves have contributed to the economic development of the world. There is a point of equilibrium and intersection between thermal properties of leaves, most leaves behavioural pattern at high temperature suggest their ability to survive at hot temperature (Georgiev and Iannacchione, 2015). The objective of this paper is to investigate the behavioural pattern of the aforementioned leaves by subjecting them to different temperatures and assess their survival and medicinal potential for economic growth.

\section{MATERIALS AND METHOD}

The research was conducted between November and December, 2016 in Esan West Local Government Council of Edo State. The experimental work was carried in Samuel Adegboyega University laboratory. During the study, selected tropical plant leaves mentioned above were collected from their various stems and their masses (gram) were taken using automatic weighing balance scale. The research was conducted between June and July 2016. The leaves were prepared using dissector and laboratory heating machine. These leaves were subjected to a rise in temperature from $40^{\circ} \mathrm{C}$ to $120^{\circ} \mathrm{C}$. The processes were repeated again to obtain more accurate results. After the heating, the leaves were put back into the automatic weighing balance scale to determine the difference in mass (gram). The mass difference, $M_{d}$ is calculated as;

$$
M_{d}=M_{b}-M_{a}
$$

Where $M_{b}$ is the initial mass before the leaves were subjected to heating and $M_{a}$ is the mass after the leaves had been subjected to heating.

\section{RESULTS AND DISCUSSION}

The effect of thermodynamic in plants with respect to the experiment conducted is obvious. From the results we found that some leaves can withstand up to $100^{\circ} \mathrm{C}$ before the heat effect is felt, this corroborates Clark (2004) findings. The first law talks about heat changes i.e. thermodynamics and heat can be defined as the quantity of energy that flows across the boundary of a system during a change in its surroundings ((Arovas, 2013), relating this to the experiment performed on plant in the laboratory, the plant goes into a non-adiabatic system where there is exchange of energy and heat is allowed in and out of the system, the plants in ordered state, when thermal process has occurred on the plant, it came out reduced in size and shape meaning the moisture content has disappeared living the leaf/plants in a disordered form obeying the second law of thermodynamics. In determining the effect of thermodynamic on plant, there were no thermal balances between the leaves. For example some plant heated up to $120^{\circ} \mathrm{C}$. Odorak, Pennisetum, Guajara, Bambusa, etc. show that they cannot survive a heated environment. It can therefore be suggested that when under preparation for economic or medical usage the effect of heat should be given serious consideration. Dioscorea, Tridax, Mangifera (Table 1) and Papaya dried exactly at $100^{\circ} \mathrm{C}$, which shows the tendency of the bonds are easily broken. The data in table 1 shows that Colocasia Esculenta has the highest mean change in mass as temperature rises, followed by Papaya. This implies that Colocasia Esculenta has the highest resistance mean compared to the other nine tropical leaves investigated.

\begin{tabular}{lccc}
\multicolumn{4}{c}{ Table 1: Statistical interpretation of results } \\
\hline $\begin{array}{l}\text { Plants leaves subjected to } \\
\text { rise in temperature }\end{array}$ & $\begin{array}{l}\text { 25\% percentiles of change } \\
\text { in mass (gram) }\end{array}$ & $\begin{array}{l}\text { Mean change in } \\
\text { mass (gram) }\end{array}$ & $\begin{array}{l}0.5 \% \text { confidence } \\
\text { of change in mass (gram) }\end{array}$ \\
\hline Dioscorea Alata & 0.748 & 1.102 & 0.252 \\
Chromolaena Odorak & 0.365 & 0.362 & 0.110 \\
Pennisetum Purpureum & 0.707 & 0.704 & 0.238 \\
Tridax Procumbens & 2.046 & 0.231 & 0.078 \\
Mangiferal Indica & 1.595 & 0.962 & 0.324 \\
Psidium Guajara & 0.374 & 0.365 & 0.112 \\
Bambusa Vulgaris & 0.242 & 0.241 & 0.073 \\
Manihot Esculenta & 6.575 & 0.747 & 0.252 \\
Colocasia Esculenta & 6.892 & 4.744 & 2.079 \\
Carica Papaya & 4.712 & 3.307 & 1.115 \\
\hline
\end{tabular}


In conclusion, the thermodynamical effect of selected tropical leaves and their behavioural pattern were studied. It was discovered that some plants can survive in an environment with rising temperature while some cannot survive when the temperature is fast increasing. In the light of these findings, we recommend further investigation into these selected tropical plants leaves to determine whether thermal influence can reduce their productivity when there are reductions in their masses? Does it have effect in their chemical constituents?

\section{REFERENCES}

Ahmad, N; Fazal, H; Ayaz, M; Abbasi, BH; Mohammad, I; Fazal, L (2011). Dengue fever treatment with Carica papaya leaves extracts. Asian Pacific Journal of Tropical Biomedicine, 1(4): 330-333.

Al-Shemmeri, $\quad$ T (2010). Engineering Thermodynamics. Tarik Shemmeri and Ventus Publishing, ApS.

Arovas, D (2013). Thermodynamics and Statistical Mechanics (A Work in Progress), Department of Physics, University of California, USA.

Bettini, A (2017). A Course in Classical Physics 1 Mechanics (Undergraduate Lecture Notes in Physics). Springer International Publishing, Switzerland.

Bettini, A (2016). A Course in Classical Physics 2 Fluids and Thermodynamics (Undergraduate Lecture Notes in Physics). Springer International Publishing, Switzerland.

Clark, JOE (2004). The Essential Dictionary of Science. Barnes \& Noble Books, New York.

Georgiev, G; Iannacchione, G (2015). Selforganization in non-equilibrium systems. Bulletin of the American Physical Society, 60(1).
Gyftopoulos, EP; Beretta, GP (2005). What is the second law of thermodynamics and are there any limits to its validity? Elsevier Science, pp.1- 44.

Haase, R (1969). Thermodynamics of Irreversible Processes, translated in English, AddisonWesley, Reading, MA, pp. 10-11.

Hoch, MJR (2011). Statistical and Thermal Physics: An Introduction. CRC Press, Taylor and Francis Group, USA, pp. 15-17.

Lucas, J (2015a). What is the First Law of Thermodynamics? Live Science Contributor. Retrieved 13 November, 2017 from https://www.livescience.com/50881-first-lawthermodynamics.html.

Lucas, J (2015b). What is Thermodynamics? Live Science Contributor. Retrieved 13 November, 2017 from https://www.livescience.com/50776thermodynamics.html.

Purcell, ME (1977). Physics and Our World. Lyman Laboratory, Harvard University, Cambridge, Massachusetts, USA.

Reif, F (2009). Fundamentals of Statistical and Thermal Physics, Waveland Press, USA, pp. 122.

Singal, RK; Singal, M (2009). Engineering Thermodynamics. I. K. International Pvt Ltd, pp. 20.

Smith, JM.; Van Ness, HC; Abbott, MM (2005). Introduction to Chemical Engineering Thermodynamics. McGraw Hill. New York.

Wu, T. (1969). On the Nature of Theories of Irreversible Processes. Inter. J. Theory. Phy. 4(2): 325-343. 